\title{
Adulterated Cocaine and Lessons Learned from the Jake Walk Blues
}

\author{
Timothy J. Wiegand
}

Published online: 11 March 2010

(C) American College of Medical Toxicology 2010

Keywords Levamisole-adulterated cocaine - TOCP.

Jamaican ginger extract $\cdot$ Cocaine $\cdot$ Adulterated-cocaine

The Substance Abuse and Mental Health Services Administration has posted a warning on their website and sent fliers to healthcare providers throughout the USA:

Nationwide Pubic Health Alert Issued Concerning LifeThreatening Risk Posed by Cocaine Laced with Veterinary Anti-Parasite Drug.

Similar reports have come out of Alberta, Canada and from Canadian public health advocacy groups-Alberta, Canada was one of the first locations where levamisoleadulterated cocaine was reported and first associated with severe health effects including death.

Since consistently turning up in cocaine seizures in 2002, the amount of cocaine adulterated with levamisole has been steadily increasing. According to Drug Enforcement Agency (DEA) data levamisole was found in over $70 \%$ of all illicit cocaine as of July 2009 [1]. The amount of levamisole encountered in cocaine typically ranges from 6 to $9 \%$ of the drug by weight and according to a recent study from Seattle, Washington nearly $80 \%$ of individuals who tested positive for cocaine also tested positive for levamisole.

Although it has been used historically as an immune modulator for diseases such as rheumatoid arthritis and as an

T. J. Wiegand $(\bowtie)$

Northern New England Poison Center, Maine Medical Center,

Portland, ME, USA

e-mail: timothywiegand@yahoo.com

T. J. Wiegand

Tufts University School of Medicine,

Boston, MA, USA adjuvant agent in anticancer therapy, levamisole is no longer approved for human use. It remains readily available, however, in pet stores throughout the USA and in Central and South America for sale as a deworming or anti-parasitic agent. A recent celebrity death brought attention to this issue. Adam Goldstein, aka DJ AM, a celebrated musician and pop DJ known for his ability to mix and blend songs together into what is referred to as 'mashups' was found dead in his apartment on August 28, 2009 of an apparent drug overdose. Although DJ AM was found to have oxycodone, cocaine, hydrocodone, alprazolam, and lorazepam in his system, toxicology results also included the chemical levamisole, presumed to have been present as a cocaine adulterant. Goldstein's death, while most likely due to the combined effects of the cocaine, opioids, and benzodiazepines has created public awareness of the cocaine epidemic and drug adulteration [2].

The Annals of Internal Medicine published a report describing five cases of agranulocytosis associated with cocaine adulterated with levamisole [3] and in Alberta, where some of the first reports of levamisole appeared, over 20 confirmed or probable cases of agranulocytosis, including at least two deaths, have been reported due to adulterated cocaine as of this past August. While levamisole may cause reversible agranulocytosis in up to $20 \%$ of individuals exposed to it, the true threat to the public health is unclear. What also remains unclear is why levamisole in particular is being used as a cocaine adulterant. Reviewing similar epidemics from history may provide some insight and understanding into this current epidemic and drug adulteration or contamination in general.

Jamaican ginger extract, also known as Jake, was a patent medicine with a high ethanol content that was available in the nineteenth and early twentieth century. Although not 
toxic or poisonous by itself, the extract contained $70-80 \%$ ethanol by weight and thus provided a convenient way to bypass prohibition laws. In order to clamp down on the diversion of Jake for use as intoxicating liquor the minimum requirements of ginger solids by milliliter of ethanol resulted in a liquid that was extremely bitter and unpalatable. US Department of Agriculture inspectors would test shipments of Jamaican ginger extract by boiling off the ethanol and water and weighing the residue. In order to circumvent this evaporation test, create a palatable beverage, and still fall within compliance of the required solid standards, bootleggers replaced the potent ginger solid extract oleoresin with small amounts of ginger and other 'solids' such as molasses or castors oil that did not evaporate nor cause distaste in those consuming the beverage for its intoxicating purpose. Two bootleggers, Harry Gross and Max Reisman, in an attempt to undercut the competition, developed a cheaper process of adulteration adding tri-ortho cresyl phosphate (TOCP) instead of the costlier molasses or castor oil. TOCP preserved the Jake's drinkability yet passed the Department of Agriculture Inspectors' analysis.

By the 1930s, Jake use was particularly prevalent in rural southern cities and counties as many of these locales had been 'dry' prior to Prohibition. In cities such as Cincinnati Jake enjoyed a particularly ardent following; in fact eight different varieties of Jake were available in Cincinnati alone. This period of time saw the emergence of phonographic recording and, in particular, the recording of southern rural artists and the subject matter and themes of folk music often explicitly related to social and cultural forces; Jake use was often mentioned in these performances. Although initially, Jake was sung about in the context of intoxication and as a wage of sin, the subject of these ballads turned more frequently to catalog and reflect upon a curious phenomenon called Jake leg; the characteristic flapping motion of Jake users' feet as they walked. In 1930, large numbers of Jake users began to lose the use of their hands and feet. Some victims could walk but had no control of the muscles in their lower legs. Their walk was of a particular pattern in which the feet and legs were lifted high and the toes hit the ground first with the heels following. Not only were Jake drinkers' gaits affected but they developed muscle pain and weakness as well. Initially called "The 1930 Type of Polyneuritis," the illness became known as "Jamaica Ginger Paralysis" or "Jake Leg Paralysis" as the association between Jake consumption and symptomology became clear. Since the use of Ginger Jake as an alcohol replacement had been common as early as the 1860s and the paralysis was first noted in 1930, confusion arose as to the exact cause of this toxicity. After a group of animals developed similar neurologic deficits upon exposure to the TOCP adulterated Jake, formal animal studies confirmed the TOCP as the cause of the ginger Jake paralysis. Ultimately, 4,837 cases of paralysis were formally reported; the true prevalence of ginger Jake's paralysis, however, is surmised to be greater than 20,000 with some experts estimating at least 60,000 Americans suffered this irreversible form of neurotoxicity [4].

While TOCP was used simply as a cheaper substitute for molasses or castor oil in the ginger extract, adulterants or contaminants may be present for a variety of reasons. With regard to cocaine, look-alike products typically included sugars such as lactose or mannitol and inositol. Local anesthetics were often added to increase the anesthetic action of the product, facilitating acceptance that a steppedon product was, in fact, of high quality. Rapid numbing of the lips, tongue, or nose upon 'sampling' was a reassurance to buyers that they were getting 'good' product. Simply substituting a look-alike chemical or substance for a drug is probably the most common type of adulteration. Sometimes, the adulterants cause significant toxicity. In 2008 in Germany, well over 100 individuals were exposed to marijuana to which particles of lead had been added to increase the weight. Over 90 patients had blood lead levels that required treatment [5]. Certain other outbreaks of toxicity are due to clandestine chemical synthesis gone wrong or in which chemists 'cut corners'. In former Soviet Union states, young 'jef' (methylcathinone) users cook ephedrine with salicylic acid and solutions containing manganese to make their drug. The manganese leads to rapid neurologic deterioration resembling Parkinsonism. One of the most unfortunate, yet serendipitous outbreaks of illness associated with illicit drug use occurred initially in 1982 as four young injection drug users in Northern California developed a rapid and irreversible Parkinsonism. The cause was found to be an impurity formed during the imperfect synthesis of a meperidine analog [6]. Despite resulting in tragic sequelae for the drug users, the impurity is now used to create an animal model of Parkinsonism and has shed light into the cause of this progressive and lethal neurologic disorder. Sometimes drugs are adulterated with more potent agents to create a 'stronger' product. Recent outbreaks related to adulteration of heroin with the potent synthetic opioid fentanyl have caused hundreds of deaths in Chicago and other parts of the Midwest. In fact, nearly 7\% of all medical examiner cases in Cook County, Illinois in 2006 were related to fentanyl adulteration [7]. Other fentanyl analogs such as 3-methyl fentanyl have been associated with several distinct epidemics of drugadulterants causing death in heroin users. Cocaine users have been exposed to other adulterant-related toxicity, sometimes purposeful. In several instances, cocainecontaining thallium which had likely been obtained from certain types of rat poison, caused skin lesions, hair loss, and other toxicity [8]. Several clusters of methemoglobinemia have been related to benzocaine-adulterated cocaine [9] 
and clenbuterol as well as scopolamine have caused toxicity in both cocaine and heroin users [10].

Although it appears that most cocaine on the market is adulterated with levamisole, diltiazem and hydroxizine have also been noted by DEA chemists, also at levels ranging from $5-10 \%$. Some individuals have hypothesized that certain adulteration patterns represent a chemical signature from which various drug cartels are able to trace and identify their product if need be.

While the accidental contamination of drugs from a botched synthetic method or imperfect purification processes, or the substitution of drugs for others with similar clinical effects or even the cutting or adulterating with cheaper agents or inert substances to increase weight and thus profit are understandable, it remains unclear why levamisole is being used as a cocaine adulterant. While some formulations of levamisole appear as a bulky white powder, other substances, such as lactose, are cheaper, on a weight-weight basis. In Internet chatrooms, related to popular culture and drug use (www.Bluelight.com) individuals have postulated that levamisole-contaminated cocaine is a US government conspiracy to disrupt the demand for illicit drugs and curtail drug cartel profits. Other theories relate to the possibility that levamisole is being used as a cocaine potentiator. Often cited in support of this theory is a paper in neuroimmunology in which an interaction between levamisole and the endogenous opiate system is explored. Specifically, levamisole was found to affect endogenous opiate levels, including codeine and morphine [11].Other theories include the idea that levamisole adulteration of cocaine may affect the ability of dogs to smell cocaine or perhaps 'confuse' chemical or analytical methods for detecting cocaine.

Although the specific reasons levamisole is being used as cocaine adulterant remains unclear and as the recent outbreaks related to contaminated heparin and melamine attest, drug adulteration is big business in both licit and illicit arenas. The New York Times featured a headline, "Adulterated Cocaine" in December 1887, only decades after cocaine was first even successfully extracted from the coca leaf [12]:

"The drug trade just now is following the cocaine market with a great deal of interest. Large sales have been made at very low prices, notwithstanding the fact that coca leaves have been and are still very scarce. Speaking of this yesterday, Mr. H.E. Alt, a large manufacturers' agent, said the low market had attracted such marked attention that several druggists had had a number of analyses made by Eastern chemists, and the latter had reported their tests running from one-half to three-fourths borax and a very small proportion of genuine cocaine. Pulverized borax has very much the same appearance as cocaine, and but few experts could tell the difference without a critical examination. The discovery of the fraud has caused a great deal of excitement in the trade, as it is particularly felt in the preparation of solutions."

It remains to be seen what impact the levamisole adulteration will have on cocaine use. Certainly some individuals may choose to abstain, unwilling to accept the risk to their health. Other individuals, who have more resources at their disposal, may choose to have their drugs analyzed for impurities - various drug testing websites that have historically analyzed 'Ecstasy' tablets, are offering, for a fee, their services in testing cocaine. Most illicit drug users, with the understanding that the drugs they ingest often vary in purity and quality and usually willing to accept a certain degree of contamination or adulteration at baseline, will simply choose to use cocaine. As with alcohol during Prohibition and the TOCP-associated epidemic of paralysis, the production and distribution of illicit drugs incorporate the perfect confluence of absence of regulation and incentive for increasing profits that will continue to provide a strong motivation for adulteration.

While illicit drugs are potential sources of toxicity, adulterated drugs have been shown to produce more toxicity and pose greater health risks than their unadulterated counterparts [13]. Perhaps this epidemic of adulteration will promote further discourse and attention to the problems which treating drug use as a criminal issue creates. Certainly, this may provide some impetus for additional discussion and interest in issues relating to harm reduction, prevention and drug abuse treatment.

"A preacher drank the ginger, he said he did it for flu, That was his excuse for having the Jake Leg too."

The Ray Brothers...

\section{References}

1. SAMHSA Press Release. www.samhsa.gov. Accessed 21 Sep 2009.

2. AP reports-DJ AM death (Adam Goldstein)

3. Zhu NY, LeGatt DF, Turner RA (2009) Agranulocytosis after consumption of cocaine adulterated with levamisole. Ann Intern Med 150(4):287-289

4. Morgan JP, Tulloss TC (1976) The Jake walk blues: a toxicologic tragedy mirrored in American popular music. Ann Intern Med 85:804-808

5. Busse F, Omidi L, Timper K, Leichtle A (2008) Lead poisoning due to adulterated marijuana. N Engl J Med 358(15):1641-1642

6. Langston JW, Ballard P, Tetrud JW, Irwin I (1983) Chronic parkinsonism in humans due to a product of meperidine-analog synthesis. Science 219:981-982

7. Schumann H, Erickson T, Thompson TM, Zautcke JL, Denton JS (2008) Fentanyl epidemic in Chicago. Illinois and surrounding Cook County 46:501-506 
8. Insley BM, Grufferman S, Ayliffe HE (1986) Thallium poisoning in cocaine users. Am J Emerg Med 4(6):545-548

9. McKinney CD, Postiglione KF, Herold DA (1992) Benzocaineadultered street cocaine in association with methemoglobinemia. Clin Chem 38(4):596-597

10. Weiner AL, Bayer MJ, McKay CA Jr, DeMeo M, Starr E (1998) Anticholinergic poisoning with adulterated intranasal cocaine. Am J Emerg Med 16(5):517-520
11. Spector S, Munjal I, Schmidt DE (1998) Effects of the immunostimulant, levamisole, on opiate withdrawal and levels of endogenous opiate alkaloids and monoamine neurotransmitters in rat brain. Neuropsychopharmacology 19(5):417-427

12. The New York Times, December11, 1887, "Adulterated Cocaine"

13. Brunt TM, Rigter S, Hoek J, Vogels N, van Dijk P, Niesink RJ (2009) An analysis of cocaine powder in the Netherlands: content and health hazards due to adulterants. Addiction 104(5):798-805 